\title{
EFFECT OF SLENDERNESS RATIO ON THE BEHAVIOR OF REINFORCED CONCRETE COLUMN CONFINED WITH CARBON FIBER REINFORCED POLYMER COMPOSITES UNDER AXIAL LOAD
}

\author{
HAYDER A. MEHDI ${ }^{1} \&$ MARYAM SINANRASHEED ${ }^{2}$ \\ ${ }^{l}$ AssistantProfessor, Department of Civil Engineering, Al-Mustansiryah University, Baghdad, Iraq \\ ${ }^{2}$ M.Sc. Student, Department of Civil Engineering, Al-Mustansiryah University, Baghdad, Iraq
}

\begin{abstract}
The present paper deals with the analysis of experimental results, obtained from tests on circular reinforced concrete $(\mathrm{RC})$ columns, confinement with external carbon fiber reinforced polymer (CFRP) sheets. Two parameters were studied, including the number of CFRP wrap layers and slenderness ratio of the columns (24, 36 and 48).Twelve circular RC columns were tested under pure axial compression load to failure. Crack and failure load have been recorded, to evaluate the load -displacement behavior, ultimate strength, and ductility of the specimens. Resultsconspicuously demonstrate that, wrapping with CFRP can enhance the structural performance of RC columns, by providing higher load carrying capacity and ductility, compared to unwrapped RC columns. The effects of test parameters are evidenced and compared.
\end{abstract}

KEYWORDS: RC Column, CFRP, Confinement \& Slenderness

Received: Sep 14, 2017; Accepted: Oct 02, 2017; Published: Nov 02, 2017; Paper Id.: IJCSEIERDDEC20171

\section{INTRODUCTION}

Reinforced concrete (RC) columns, as a major supporting element for any structure,for numerous reasons, need strengthening, and it could be a change in the use of structure or removal of some adjacent load bearing structural members, or when the column is sought to be used in a different way from previously planned, or because it is damaged by external factors during its service. Fiber composites (FRP) sheets can be used, to wrap column's cross section[1], which takes the role of the principal load-bearing constituent, and the resin (matrix) is used to relate the fibers together, transfer the force between the fibers and to protect the fiber against external mechanical and environmental damage.FRP offer significant advantages in strength and stiffness. No yielding is exhibited in FRP materials, but instead they are elastic up to failure[2].

As for carbon fiber reinforced polymer composites (CFRP), has considerably improved the flexural strength; shear strength and ductility improvement of concrete structure. The CFRP is used for strengthening and reforming of beams, bridges, slabs and columns. CFRP is chosen as strengthening material because of its great tensile strength and stiffness compared to those of other composite materials. [3]

Some investigations on FRP strengthened concrete columns under axial load have been done by researchers (Teng and Lam (2002)[4],showed that the axial compressive strength CFRP-confined concrete in elliptical specimens is controlled by the amount of confining CFRP and the major-to-minor axis length ratio of the column section, So, they found that, confining CFRP becomes more effective as the section becomes more 
elliptical, Esfahani, M.R. and Kianoush, M.R. (2005)[5], study on the axial compressive strength of RC columns (square with sharp and rounded corners) strengthened with FRP wrap and establish that, the square column with rounded corners showed a greater strength and ductility, compared to those with sharp corners by FRP warp. Similar results were recorded by Al-Salloum (2007), [6]but under uniaxial compression, Manuel Silva. (2011)[7], found that, the efficacy of confinement $\mathrm{RC}$ columns with CFRP or AFRP is known to be more preponderant,for specimens of circular cross-section than for those of rectangular section under axial load, due to the singularity and stress concentration, introduced at the edges and the reduced confinement on the flat sides.Taghia, P. and Suhaimi Abu Bakar (2013)[8], found that, externally bonded CFRP sheets are very effective in enhancing the axial strength and ductility of the concrete short columns, under pure axial static load by using Nonlinear finite element analysis (NLFEA). Inspection of the results shows that, there is good agreement between the NLFEA and the experimental test results, A. Sulaiman, H. et al., (2016)[9], shows that, parameters such as fiber orientation, stacking sequence, and number of confinement layers have a direct impact on the strength, ductility and stress-strain behavior of CFRP confined cylinder concrete column under pure axial compressive loading.The same observations were noted by Li and Hadi (2003, 2004)[10, 11], under eccentric load.

And some investigate the performance of the strengthening RC column with a FRPunder eccentric load, such as(Hadi. (2006)[12], Study eccentrically plain concrete short circular columns, warped with CFRP and E-glass FRP strips. He presentedthat; the eccentric load could noticeably lower down the maximum failure load of FRP-confined concrete columns, compared to the columns under concentric load. However, compared to the internal RC columns, FRP-confined columns exhibited a greater load capacity and ductility, when tested in both concentrically and eccentrically; similar explanations were noted by Hadi (2007)[13], using the high strength RC circular columns, Rahai et al (2008)[14], presented confirmed substantial improvement in the compressive strength, stiffness, and ductility of the CFRP-wrapped concrete cylinders, as compared to unconfined concrete cylinders under uniaxial compression, A. P. D. YarubGatiaAbtan, L. D. Hassan, F. H., and L. D. Hayder A. M.(2015)[15], explore on extremely-high strength reactive concrete (RPC) columns before and after CFRP strengthening sheets indicated that, CFRP jacketing rises the ultimate failure load of strengthened columns and let more ductile failure than the original columns. Similar results were also distinguished by Abbassi, M. and Dabbagh, H. (2014)[16], using finite element model and also Adnan R. Malik and Stephen J. Foster (2010)[17], ElMaaddawy and El-Sayed (2011)[18]).

Only a few investigations have studied the slenderness ratio of concrete columns, confinement with FRP (Chikh, N., Mesbah, H., M. Gahmous, M. and Benzaid, R. (2011)[19], found that, CFRP sheets can improve the structural act of RC columns under axial compression, in terms of both maximum strength and ductility, with change in columns slenderness ratio, form of the section (circular and square) and the number of wrap layers.

\section{EXPERIMENTAL PROGRAM}

The experimental program of this study was divided into four groups that were investigated, and the performance of circular RC columns strengthened by CFRP composite, under pure axial compression load,which was conducted at the laboratories of the College of Engineering, Al-Mustansiriya University, Iraq.The columns performance was estimated by their load carrying capacity and ductility investigation. Details of the main stages are given below.

\section{MATERIAL PROPERTIES}

Testing specimens has average 28-days compressive strength of $34 \mathrm{MPa}$, which was determined by conducting 
tests on $150 \mathrm{~mm}$ diameter cylinders.The normal strength concrete mix was used to make the test specimens. As shown in table 1

Table 1: Properties of Mixture Detailsfor $\left(1 \mathrm{~m}^{3}\right)$ of Concrete Trail Mix

\begin{tabular}{|l|l|c|c|c|c|c|}
\hline \multirow{2}{*}{ Mix No. } & \multirow{2}{*}{ W/CRatio } & \multicolumn{4}{|c|}{ Mix Proportions $\left(\mathbf{k g} / \mathbf{m}^{\mathbf{3}}\right)$} & Compressive Strength $\boldsymbol{f c}$ (MPa) at 28 days \\
\cline { 3 - 7 } & & $\mathrm{W}$ & $\mathrm{C}$ & $\mathrm{S}$ & $\mathrm{G}$ & \\
\hline 1 & 0.45 & 160 & 400 & 600 & 1200 & 34 \\
\hline
\end{tabular}

The materials used through this study were ordinary Portland cement (type I), Normal weight natural sand with $4.75 \mathrm{~mm}$ maximum size with rounded-shape particles and smooth texture and Crushed gravel with a maximum size of $12 \mathrm{~mm}$.

Two types of steel reinforcements were used, deformed steel bars $\varnothing 4$ and $\varnothing 6$ for longitudinal reinforcement and deformed steel bars $\varnothing 4$ for transversal reinforcement (ties) at the top and bottom only. The tensile strength of the reinforcement steel bars was conducted as shown in table 2.

Table 2: Specification and Test Results of Steel Reinforcing Bar Values

\begin{tabular}{|c|c|c|c|c|}
\hline No. & $\begin{array}{c}\text { Nominal Diameter } \\
(\mathbf{m m})\end{array}$ & $\begin{array}{c}\text { Yield stressf } \\
(\mathbf{M P a})\end{array}$ & $\begin{array}{c}\text { Ultimate Stressf } \\
(\mathbf{M P a})\end{array}$ & $\begin{array}{c}\text { Elongation at ultimate stress } \\
(\mathbf{\%})\end{array}$ \\
\hline 1 & 4 & 330.7 & 423.5 & 2.11 \\
\hline 2 & 6 & 469.54 & 610.72 & 2.04 \\
\hline
\end{tabular}

Each Value is an Average of Three Specimens (each $50 \mathrm{~cm}$ long)

The fiber composite used for wrapping the column specimens was CFRP SikaWrap-301C product. The epoxy resin Sikadur-330 was used, to bond the carbon fabrics over the columns.Table 3 and 4, shows the properties of CFRP sheets and epoxy that is used in the experimental work, of the recent study.

Table 3: Properties of Carbon Fiber Fabric (SikaWrap -301 C) (*)

\begin{tabular}{|l|l|}
\hline Fiber Type & High strength carbon fibers \\
\hline Fiber Orientation & $\begin{array}{l}0^{\circ} \text { (unidirectional). } \\
\text { Warp: black carbon fibers (99\% of total areal weight). } \\
\text { Weft: white thermoplastic heat-set fibers (1\% of total } \\
\text { areal weight) }\end{array}$ \\
\hline Areal Weight & $304 \pm 10 \mathrm{~g} / \mathrm{m}^{2}$ (carbon fibers only) \\
\hline Fabric Design Thickness & $0.167 \mathrm{~mm}$ (based on fiber content) \\
\hline Fiber Density & $1.82 \mathrm{~g} / \mathrm{cm}^{3}$ \\
\hline Tensile Strength of Fibers & $4900 \mathrm{MPa}$ \\
\hline Tensile E - Modulus of Fibers & $230 \mathrm{GPa}$ \\
\hline
\end{tabular}

(*) Providing by the manufacturing specification

Table 4: Properties of Impregnating Resin (Sikadur-330) (*)

\begin{tabular}{|l|l|}
\hline Appearance/colours & $\begin{array}{l}\text { Part A: white } \\
\text { Part B: grey } \\
\text { Part A+B mixed: light grey }\end{array}$ \\
\hline Density & $1.30 \pm 0.1 \mathrm{~kg} / \mathrm{l}($ mixed $)\left(\right.$ at $\left.+23^{\circ} \mathrm{C}\right)$ \\
\hline Mixing ratio & $\mathrm{A}: \mathrm{B}=4: 1$ by weight \\
\hline Viscosity & Pasty, not flowable \\
\hline Tensile strength & $30 \mathrm{MPa}\left(\right.$ cured 7 days at $\left.+23^{\circ} \mathrm{C}\right)$ \\
\hline Flexural E-modulus & $3800 \mathrm{MPa}\left(\right.$ cured 7 days at $\left.+23^{\circ} \mathrm{C}\right)$ \\
\hline Tensile E-modulus & $4500 \mathrm{MPa}\left(\right.$ cured 7 days at $\left.+23^{\circ} \mathrm{C}\right)$ \\
\hline
\end{tabular}


(*) Providing by the manufacturing specification

\section{COLUMNS CONFIGURATION}

The column specimens were distributed into four groups: Group (A) content three specimens unwrapped. Group (B) content three specimens wrapped with three-layers of CFRP which have (50mm) width. Group (C) content three specimens wrapped with five-layers of CFRP which have $(50 \mathrm{~mm})$ width either distributed equally. Group (D) content five specimens wrapped all over the columns (fully wrapped) with CFRP. The columns were labeled as in Table 5.

\section{STRENGTHENING PROCEDURE}

After the preparing of the surfaces and making sure clean and dry; The two parts of adhesive (gray and white) mixed together according to the manufacturer recommends, Then applied tothe Specific place of RC column by using spoonputty between the lines that laid out for CFRP location. After that CFRP was applied and handled carefully with a $20 \mathrm{~mm}$ overlap.Once the relevant layer of fabric was wrapped, another coat of the epoxy resin was applied.After the application process had been completed. The specimens remained in its place for one week before being tested. After finishing the CFRP installation, and before the testing date, all concrete surface specimens were painted white to distinguish the crack propagation easily.The fixed procedure of CFRP on the RC column surface is shown in plate 1.

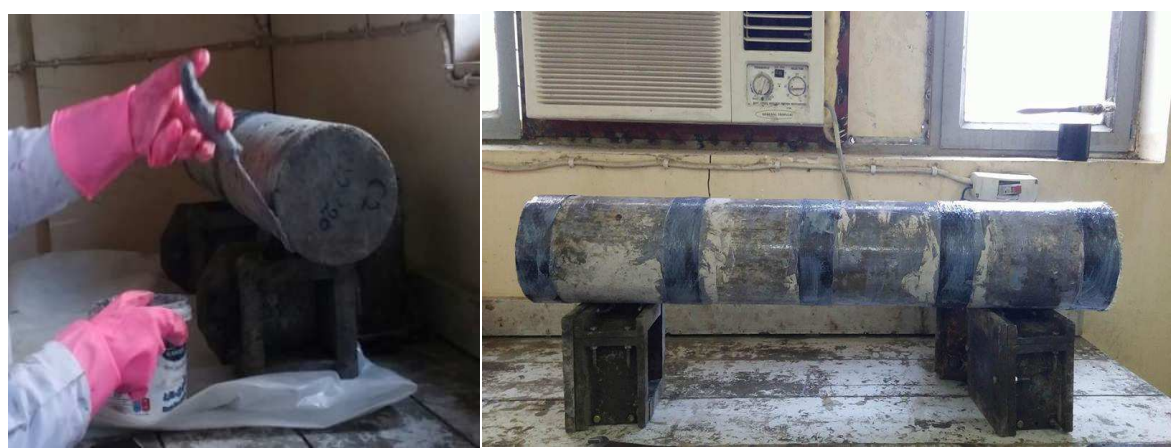

Plate 1:The Fixed of CFRP Procedure

\section{DETAILS OF COLUMNS SPECIMENS}

In this study twelve normal strength RC circular columns were cast and tested, four columns with dimension $(75 \times 900) \mathrm{mm}$, four columns with dimension $(100 \times 900) \mathrm{mm}$ and four columns with dimension $(150 \times 900) \mathrm{mm}$. Therefore, the columns with $\operatorname{dim}(75 \times 900) \mathrm{mm}$ had four $\varnothing 4 \mathrm{~mm}$ diameter deformed bars and the columns with $\operatorname{dim}((100 \times 900)$ and $(150 \times 900)) \mathrm{mm}$ had three and seven $\varnothing 6 \mathrm{~mm}$ deformed bars, respectively as longitudinal steel reinforcement and $\emptyset 4 \mathrm{~mm}$ deformed bars, for all columns as transverse steel reinforcement (ties), at $100 \mathrm{~mm}$ from edge of longitudinal bars on top and bottom. Figure 1, shows the geometry and reinforcement details of the specimens. The test program and specimen details are summarized in Table 5.and CFRP distribution is shown in Plate 1. 


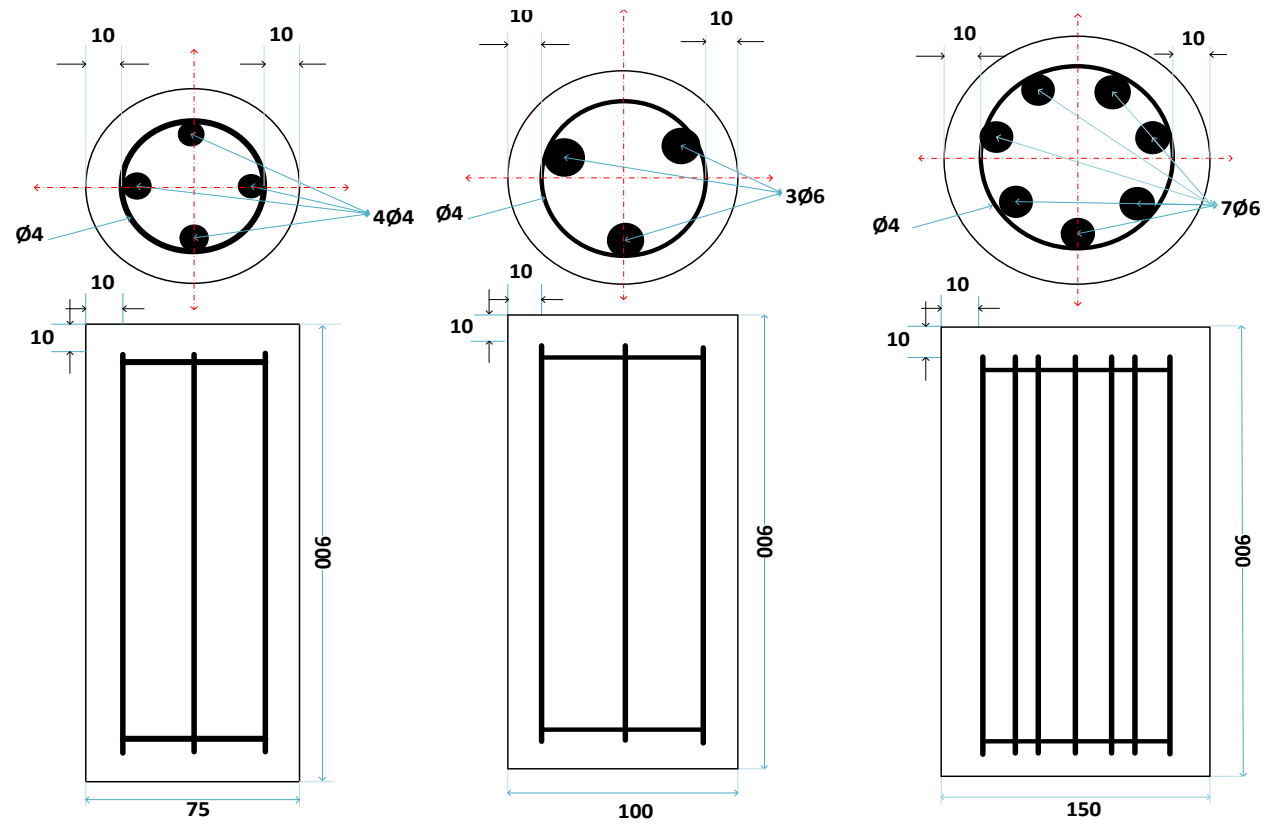

Figure 1 Details of loading and specimens.

All dimensions in ( $\mathrm{mm})$

Table 5: Details of Test Specimens

\begin{tabular}{|c|c|c|c|c|c|c|}
\hline Col. No. & $\begin{array}{l}\text { Group } \\
\text { Name }\end{array}$ & Column Symbol & $\begin{array}{l}\text { Col. Diam. } \\
\quad(\mathrm{mm})\end{array}$ & $\begin{array}{c}\text { Reinforcement } \\
\text { ratio } \%\end{array}$ & $\begin{array}{l}\text { No. of } \\
\text { CFRP } \\
\text { Layer } \\
\end{array}$ & $\begin{array}{c}\text { Width of } \\
\text { CFRP Layer } \\
(\mathrm{mm})\end{array}$ \\
\hline 1 & \multirow{3}{*}{$\operatorname{Group}(A)$} & GAR37.5\#C0 & 75 & $\rho_{\min }=1.138$ & ---- & ---- \\
\hline 2 & & GAR50\#C0 & 100 & $\rho_{\min }=1.08$ & ----- & ----- \\
\hline 3 & & GAR75\#C0 & 150 & $\rho_{\min }=1.12$ & ----- & ----- \\
\hline 4 & \multirow{3}{*}{ Group(B) } & GBR37.5\#C3 & 75 & $\rho_{\min }=1.138$ & 3 & 50 \\
\hline 5 & & GBR50\#C3 & 100 & $\rho_{\min }=1.08$ & 3 & 50 \\
\hline 6 & & GBR75\#C3 & 150 & $\rho_{\min }=1.12$ & 3 & 50 \\
\hline 7 & \multirow{3}{*}{$\operatorname{Group}(\mathbf{C})$} & GCR37.5\#C5 & 75 & $\rho_{\min }=1.138$ & 5 & 50 \\
\hline 8 & & GCR50\#C5 & 100 & $\rho_{\min }=1.08$ & 5 & 50 \\
\hline 9 & & GCR75\#C5 & 150 & $\rho_{\min }=1.12$ & 5 & 50 \\
\hline 10 & \multirow{3}{*}{ Group(D) } & GDR37.5\# $C_{\text {Full }}$ & 75 & $\rho_{\min }=1.138$ & Full & 900 \\
\hline 11 & & GDR50\# $C_{\text {Full }}$ & 100 & $\rho_{\min }=1.08$ & Full & 900 \\
\hline 12 & & GDR75\# $C_{\text {Full }}$ & 150 & $\rho_{\min }=1.12$ & Full & 900 \\
\hline
\end{tabular}

$\dagger$ †AR\#C means:

G:group of columns.

A: name of the group. (Group A)

R: radius of column.

\#C: number of CFRP layers. 


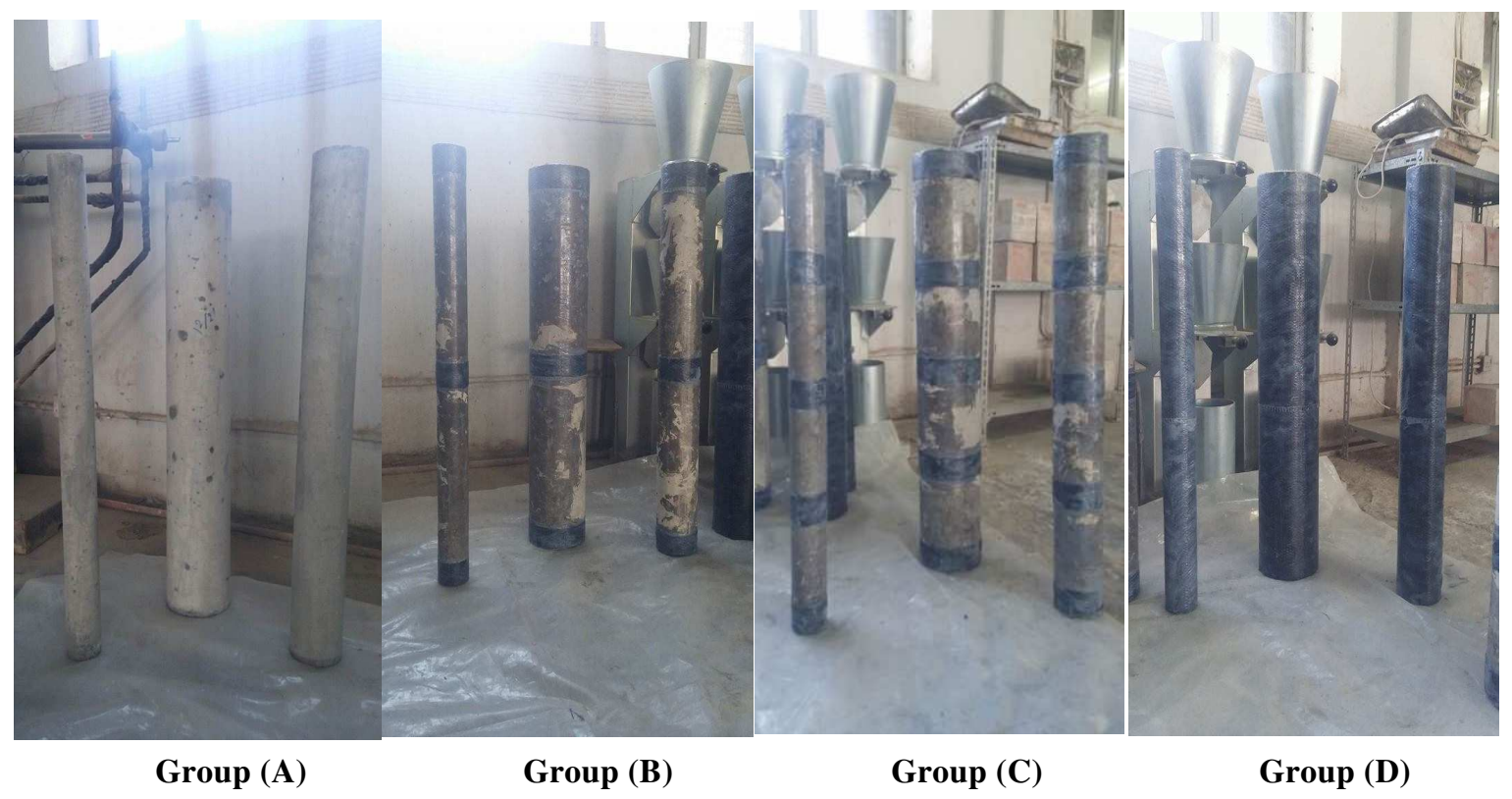

Plate 2 CFRP Distribution

\section{TEST SETUP}

Twelve columns were tested under pure axial compression loading up for failure by using the 8551MFL SYSTEM of hydraulic universal testing machine type EPP300. Plywood with a steel plate in the column ends was done first in order to obtain a uniform distributed load applied to the entire face. Two dial gauges positions were marked in the middle of each column specimen at (450mm) height, from two sides (Longitudinal, $\mathrm{X}$ and transverse $\mathrm{Y}$ ) to measure the mid-height lateral displacement (deflection) of the columnsas shown in plate 3. The result was taken from the two directions of displacement.

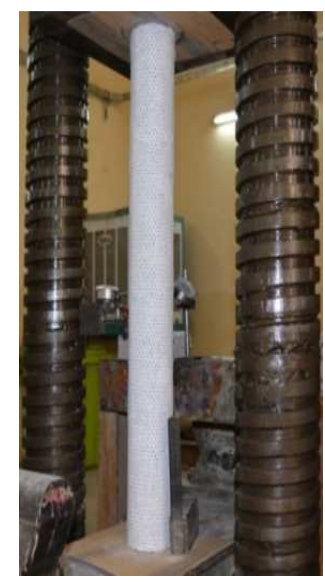

Plate 3: Test set-up of Column Specimen

\section{TEST RESULTS AND DISCUSSIONS}

The ultimate load and the corresponding lateral displacements of RC columns were recorded during the axial compression testing, which based on the slenderness ratio withCFRP distribution. The test results for all specimens are given in Table 6.After every (10 second), the load increment of the RC columns was checked for cracks and any probable failure marks. 
Table 6: Test Results and Details of Columns up to Failure

\begin{tabular}{|c|c|c|c|}
\hline Group Name & ColumnSymbol & Pu (kN)* & \% Increasing in Pu \\
\hline \multirow{2}{*}{ Group (A) } & GAR37.5\#C0 & 91 & \multirow{2}{*}{ Reference column } \\
\cline { 2 - 4 } & GAR50\#C0 & 195 & \\
\cline { 2 - 4 } & GAR75\#C0 & 517.5 & \\
\hline \multirow{2}{*}{ Group (B) } & GBR37.5\#C3 & 136 & 49.5 \\
\cline { 2 - 4 } & GBR50\#C3 & 291 & 49.2 \\
\cline { 2 - 4 } & GBR75\#C3 & 592 & 14.4 \\
\hline \multirow{2}{*}{ Group (C) } & GCR37.5\#C5 & 217 & 138.5 \\
\cline { 2 - 4 } & GCR50\#C5 & 372 & 90.8 \\
\cline { 2 - 4 } & GCR75\#C5 & 635 & 22.7 \\
\hline \multirow{2}{*}{ Group (D) } & GDR37.5\#Cfull & 270 & 196.7 \\
\cline { 2 - 4 } & GDR50\#Cfull & 562.5 & 188.5 \\
\cline { 2 - 4 } & GDR75\#Cfull & 914.5 & 76.7 \\
\hline
\end{tabular}

*ultimate load

\section{MODE OF FAILURE}

Threeof these columns were tested without strengthening for comparing with the other strengthened columns. The ultimate load equal to $(91 \mathrm{kN}, 195 \mathrm{KN}, 517.5 \mathrm{KN})$ for (GAR37.5, GAR50, and GAR75), respectively (table 6). The control specimens failed, due to the crushing of concrete (compression failure) were Cracks initiation, occurred at the top edge in the early stages of loading and propagated in the longitudinal direction of the member, with increasing of loading until failure and buckling of the longitudinal steel bar of the columns. Plate 4, shows the failure region of the unstrengthened specimens.
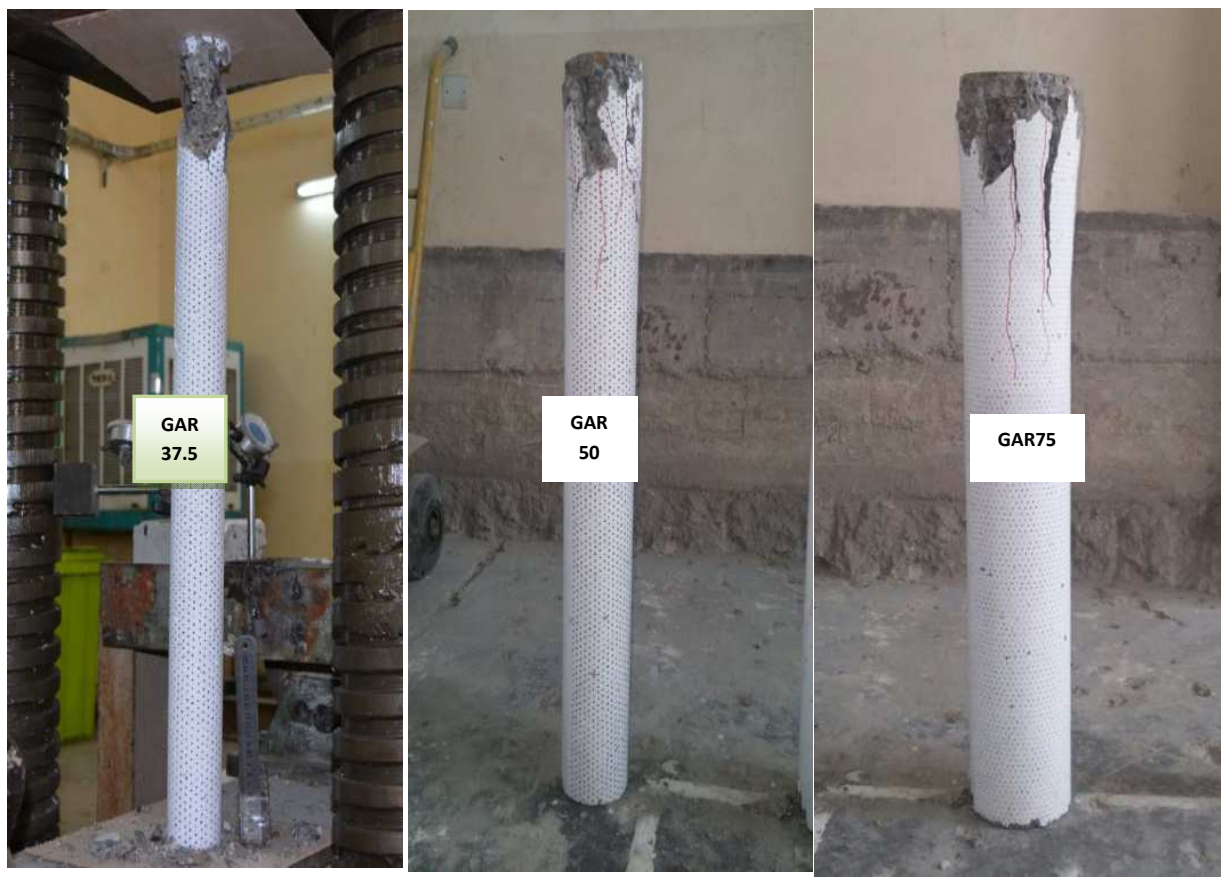

Plate 4:Shows the Failure Region of the un Strengthened Specimens

Group (B), that consisted of three columns strengthened by three strips, with $50 \mathrm{~mm}$ width which represents $17 \%$ ofthe surface area of columns, is installed on the top, bottom and center of each column, perpendicular to columns axis (plate 2). After testing, the columns seemed to have nonlinear performance, until the moment of failure was reached except specimen (GBR37.5) has a linear behavior, Specimen (GBR37.5), failed by (compression and shear) failure of 
concretewith buckling in longitudinal reinforcement, at the top as a result of the weakness of a particular area, where compression load is concentrated, which led to the failure of shear under the top strip of CFRP, due to the bond of CFRP while specimens GBR50 and GBR75 failed by (compression failure), only between the center and bottom strips of CFRP also, due to the bond of CFRP layer. The strengthened columns(GBR37.5, GBR50, and GBR75) failed at ultimate load and with an increasing $(49.5 \%, 49.2 \%, 14.4 \%)$, as compared with control columns, respectively as result of presence of CFRP sheets. Plate 5, shows the failure region of the strengthened specimens, with three layers of CFRP.

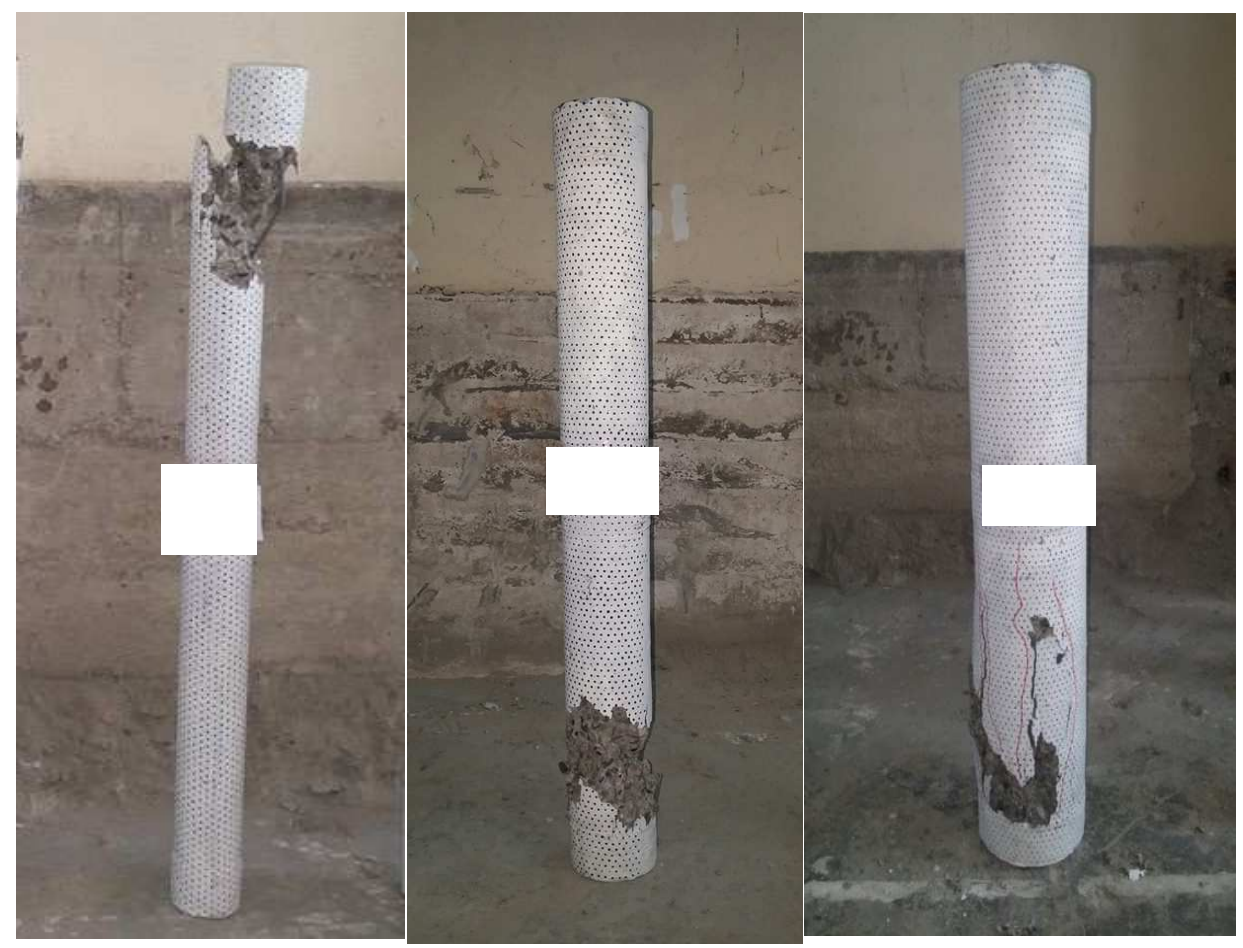

Plate 5:Failure Region of the Strengthened Specimens with Three Layers of CFRP

As for group (c), which consisted of three columns strengthened by five strips, with $50 \mathrm{~mm}$ width which represents $28 \%$ ofthe surface area of columns, is installed on the top, bottom, center of each column and between exactly at $22.5 \mathrm{~mm}$ from height on each side. These strengthened columns were tested. The columns seemed to have a nonlinear performance until the moment of failure was reached. The type of failure of these columns was (Compression failure), for specimens (GCR37.5 and GCR50) failed at top edge under the first strip of CFRPand reached near the second CFRP strip (400mm from the face of the columns), while GCR75 also failed by compression, but the cracking appeared at the top and bottom of the column, due to rupture of CFRP reaching the second strip from each side. The cracking Sound was heard, which might be an indication of rupture failure of CFRP. The strengthened columns (GCR37.5, GCR50, and GCR75) failed at ultimate load and with an increasing (138.5\%, 90.8\%, and 22.7\%), as compared with control columns, respectively. Plate 6 , shows the failure region of the strengthened specimens with five layers of CFRP. 


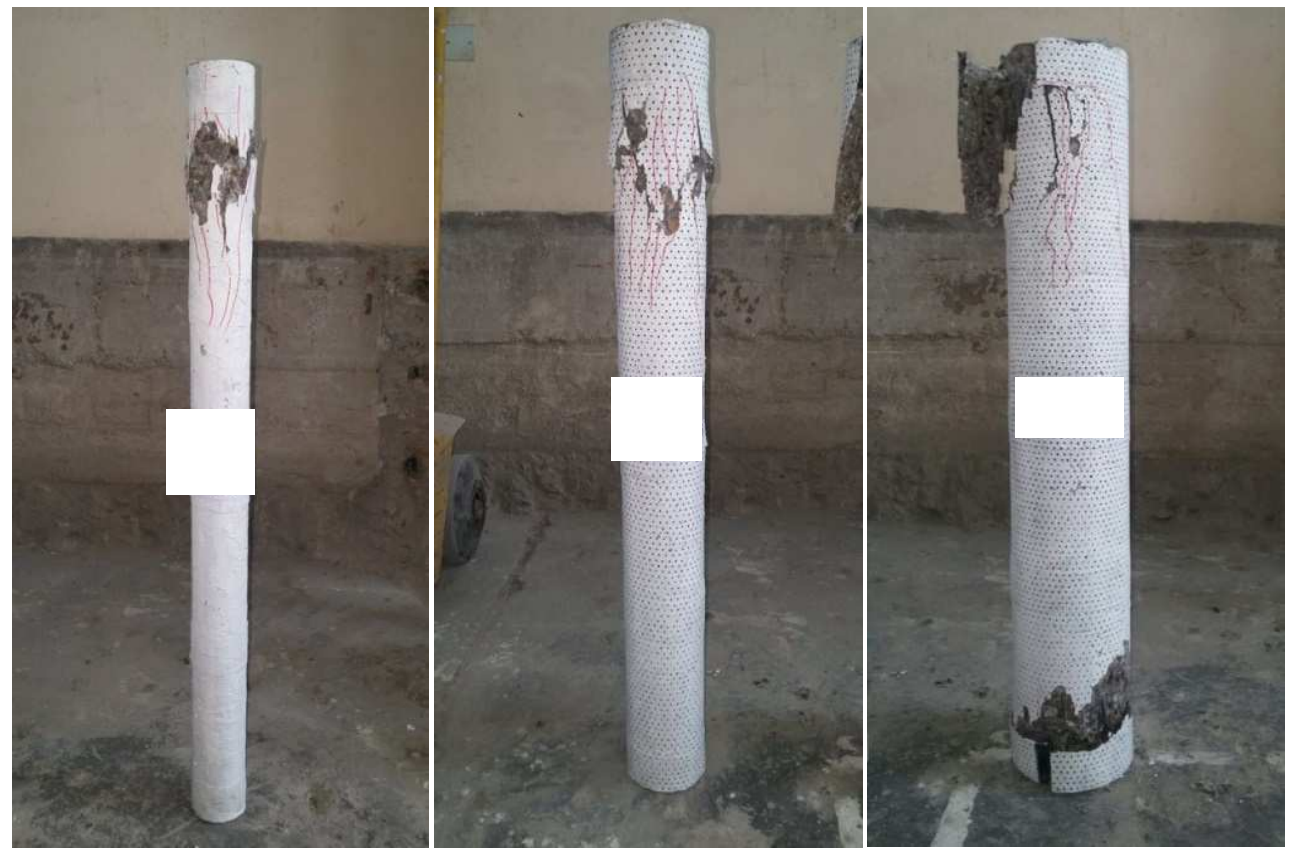

Plate 6:Failure Region of the Strengthened Specimens with Five Layers of CFRP

While the group (D) consisted of three columns strengthened by strips, which are installed on full face of each column (100\% ofthe surface area of columns), All of these concrete columns, unlike group (A), (B) and (C), failed by fracture of the composite wrap in a sudden and explosive way with creeping sounds as presented in plate 7 . These strengthened columns (GDR37.5, GDR50 and GDR75) were tested, which have a nonlinear performance until the moment of failure was reached. For column (GDR37.5), Buckling failure initiated at the middle height due to the slenderness of the column and column (GDR50) failed by buckling with shear failure also at the middle height, of column due to the strength of CFRP and slenderness ratio while column (GDR75) failed by compression failure at the bottom edge of column due to rupture of CFRP. The maximum lateral deflection was almost seen at middle height, of the specimens for (GDR37.5 and GDR50). We noticed that for slender and intermediate specimens, the fiber rupture starts mainly in their central zone and for short specimens, the collapse was mostly concentrated in their end regions, indicating that the greater the slender ratio, the smaller the area of CFRP ruptured. The noises of the stretched FRP were extremely heard and the curvature of the specimen was visible and showed buckling of the longitudinal steel bar in the columns. The sudden failure indicates the release of an extraordinary amount of energy as a result of the tensile stress provided by the FRP. The cracking behavior did not observe directly because concrete surfaces were covered by CFRP. The strengthened columns failed at ultimate load (GDR37.5, GDR50, and GDR75) and with an increasing in load (196.7\%, 188.5\%, and 76.7\%), as compared with control columns, respectively. Plate 7, shows the failure region of the strengthened specimens with full CFRP. 


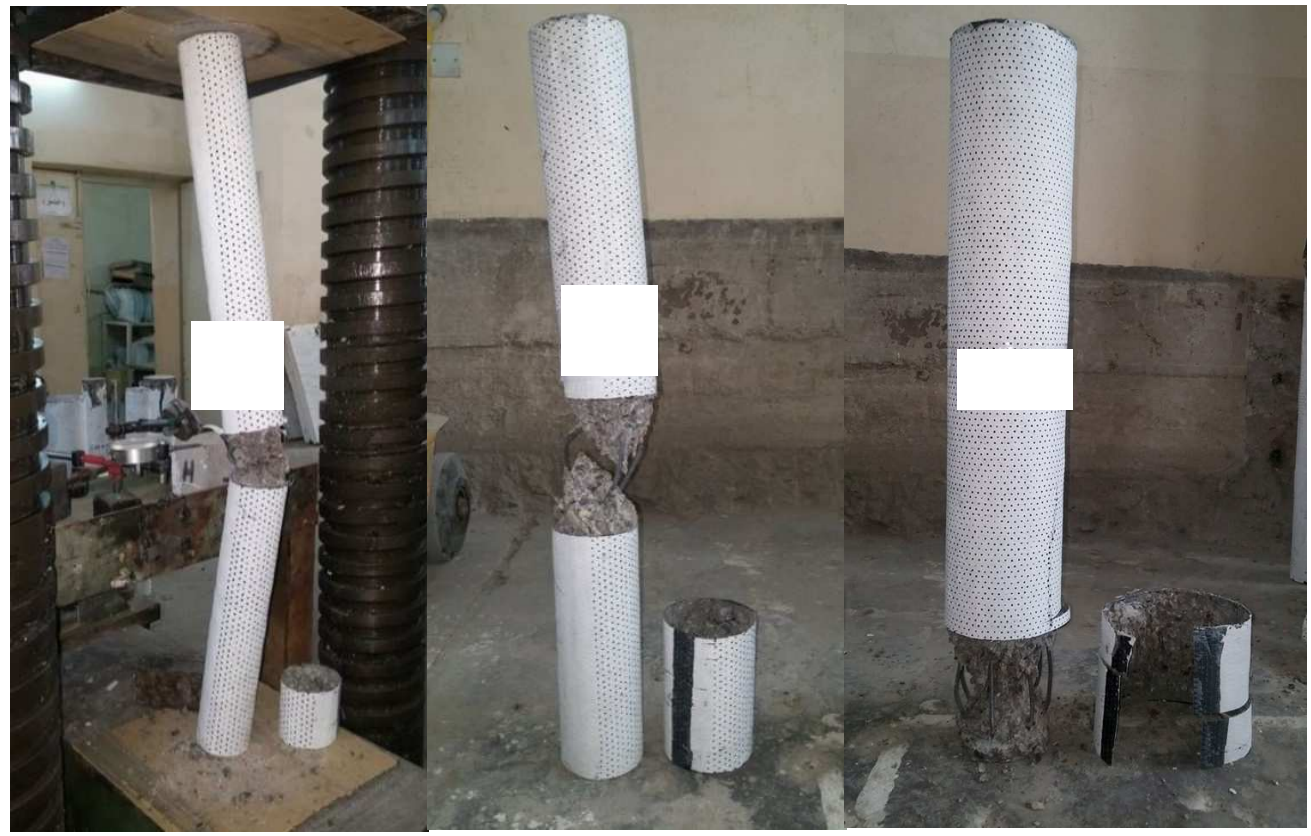

Plate 7:Failure Region of the Strengthened Specimens with Fully CFRP

\section{LOAD-DISPLACEMENT BEHAVIOR}

It is shown clearly that the control columns performed has a similar linear behavior at load-displacement curves before reaching the failure load.The point of thefirst crack load was indicated by the initial change of slope of the loaddisplacement curves.Displacements continued increasing under increasing loads until failure. The deflection of control columns (GAR37.5, GAR50, GAR75) was increased by load increasing, at ultimate load was $(1.75 \mathrm{~mm}, 1.63 \mathrm{~mm}, 0.77 \mathrm{~mm})$ respectively as shown in Figure 2.

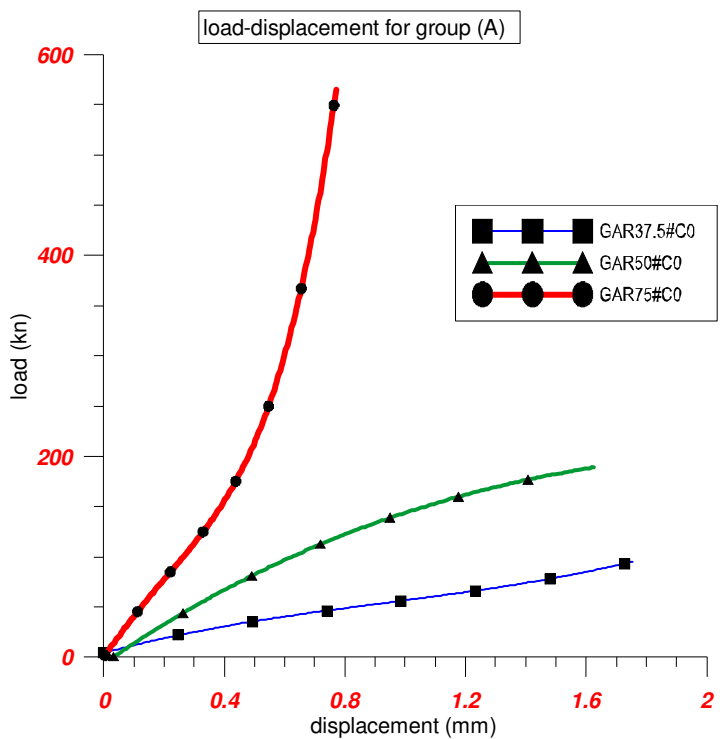

Figure 2:Load-Displacements for Columns in Group (A)

The load-displacement curves that observed have a nonlinear responseto the columns strengthened with three layers of CFRP in, mostly because the formation and propagation of longitudinal cracks in the columns unlike the control columns.Displacements continued increasing under increasing loads until failure. In group (B) (GBR37.5, GBR50, 
GBR75) the deflection was equal to $(1.71 \mathrm{~mm}, 1.59 \mathrm{~mm}, 1.52 \mathrm{~mm})$ respectively as shown in Figure 3.The differences between groups (B) and control columns was $(-2.3 \%,-2.5 \%, 67 \%)$ respectively as shown in figure 3 and 4 , a-b-c. The decreasing in the displacement of strengthening columns due to the effectiveness of CFRP make the columns less deflection with a high load, except columns (GBR75) had increased in deflection due to the failure mode which was crushed (compression failure) at the mid-height of the column.

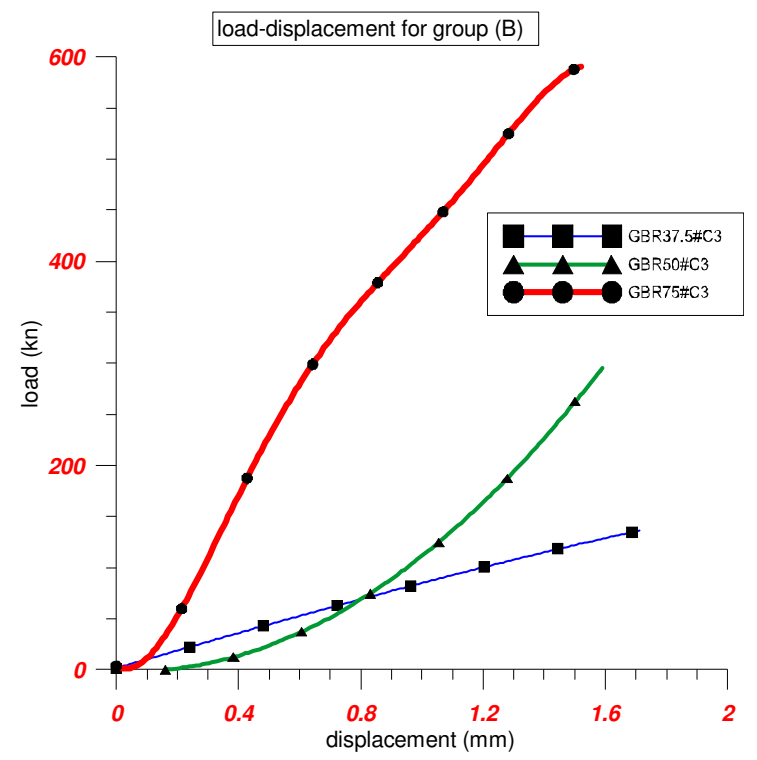

Figure 3:Load-Displacements for Columns in Group (B)
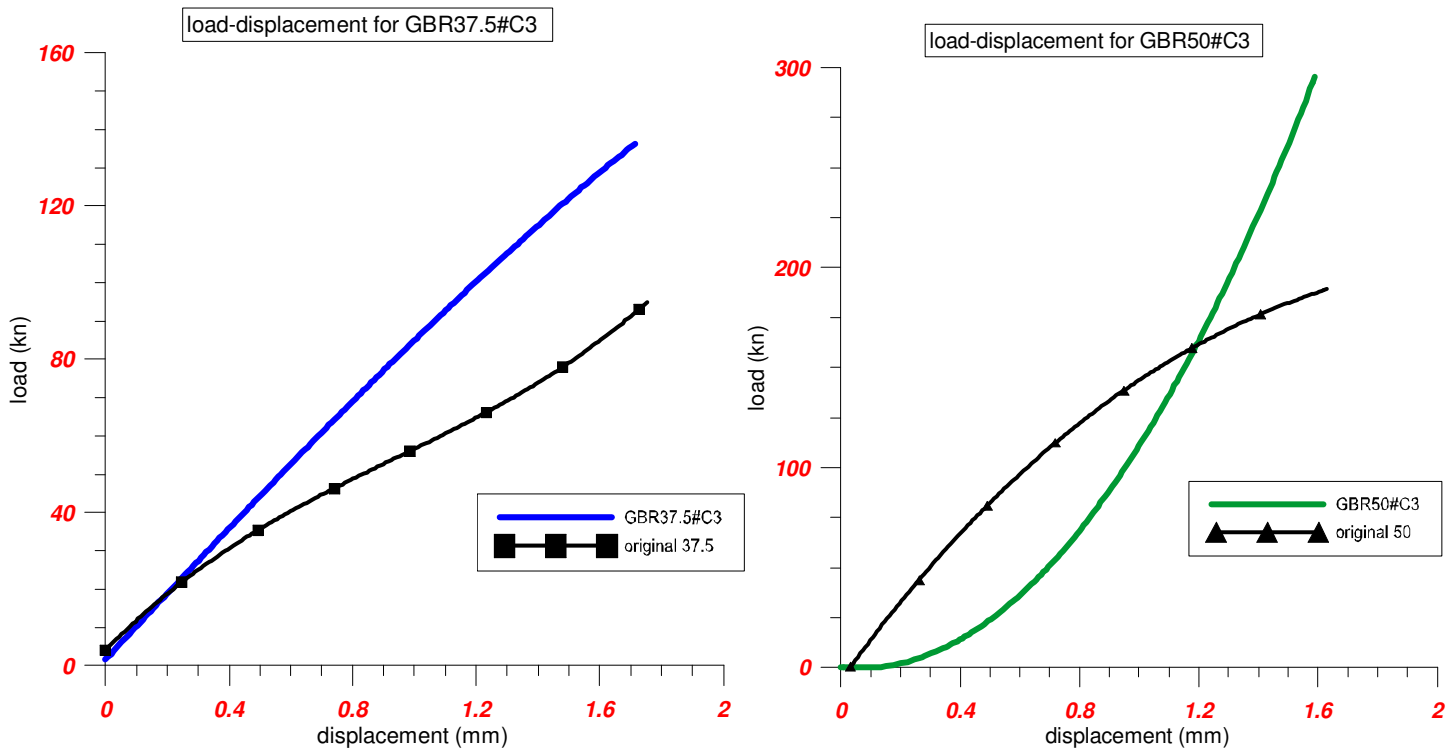

(a)SlenderColumn $(\mathrm{kl} / \mathrm{r}=48)(b)$ Slender Column $(\mathrm{kl} / \mathrm{r}=36)$ 


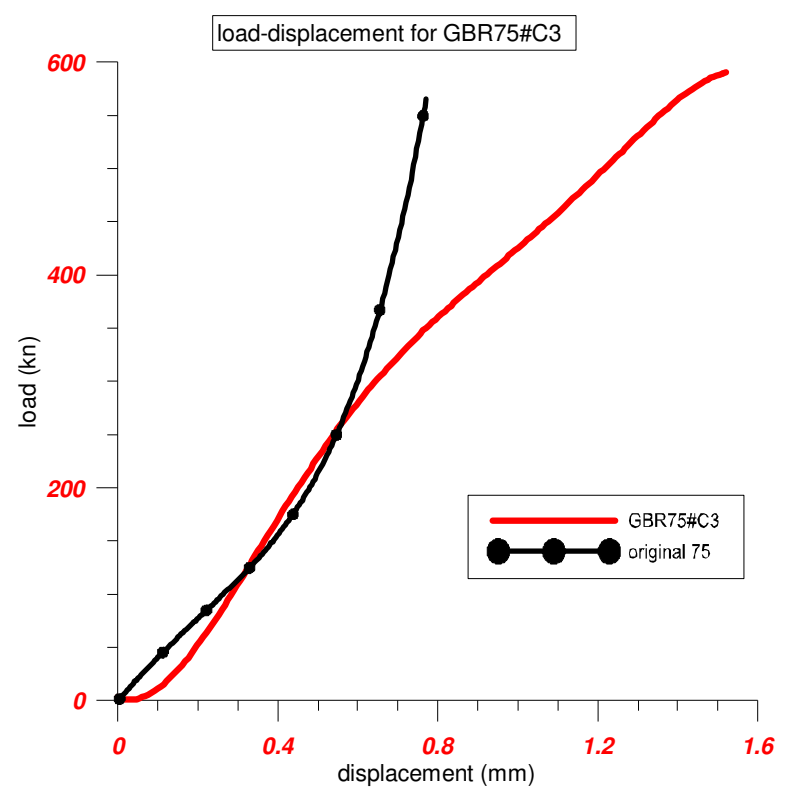

(c) Slender Column $(\mathrm{kl} / \mathrm{r}=\mathbf{2 4})$

Figure 4: Load Displacement for Each Column in Group (B) with theOriginal

In group (C), (GCR37.5, GCR50, GCR75) are the maximum deflection (1.64mm, 1.35mm, 5.46mm), respectively, the differences between group (C) and control columns was $(-6.3 \%,-17.2 \%, 609 \%)$, respectively as shown in figure 5 and 6, a-b-c. The nonlinear response that was observed in the load-displacement curves mainly, because the formation of cracks in the column. The decreasing in the displacement of strengthening columns, due to the effectiveness of CFRP make the columns less deflection, with a high load, but sometimes even with strengthening layers of CFRP and the displacement increase due to CFRP rupture. The columns continued supporting the load, until the rupture of the CFRP while experiencing a larger displacement. Buckling of longitudinal reinforcement and crushing of concrete in compression was also observed.

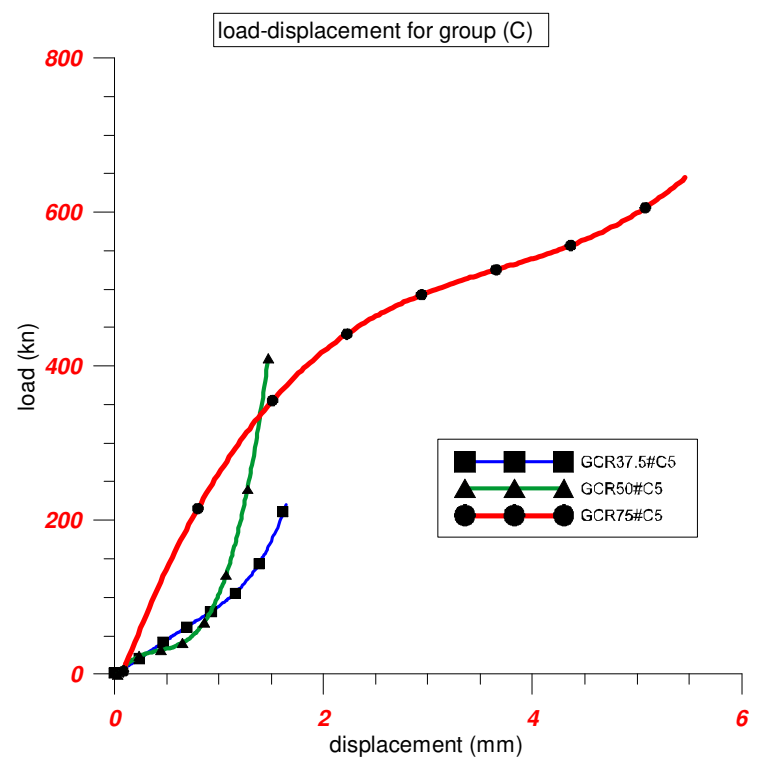

Figure 5:Load-Displacements for Columns in Group (C) 

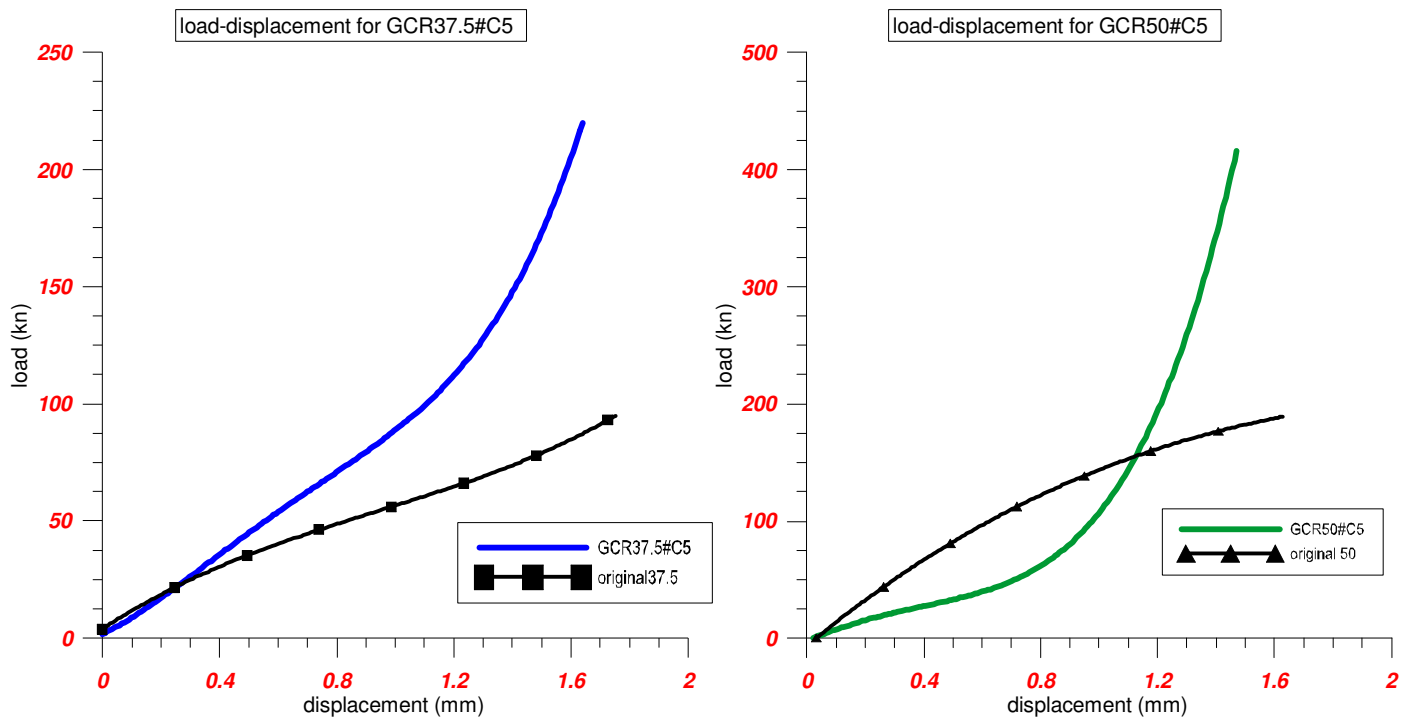

(a)Slender Column $(\mathrm{kl} / \mathrm{r}=48)(\mathrm{b})$ Slender Column $(\mathrm{kl} / \mathrm{r}=36)$

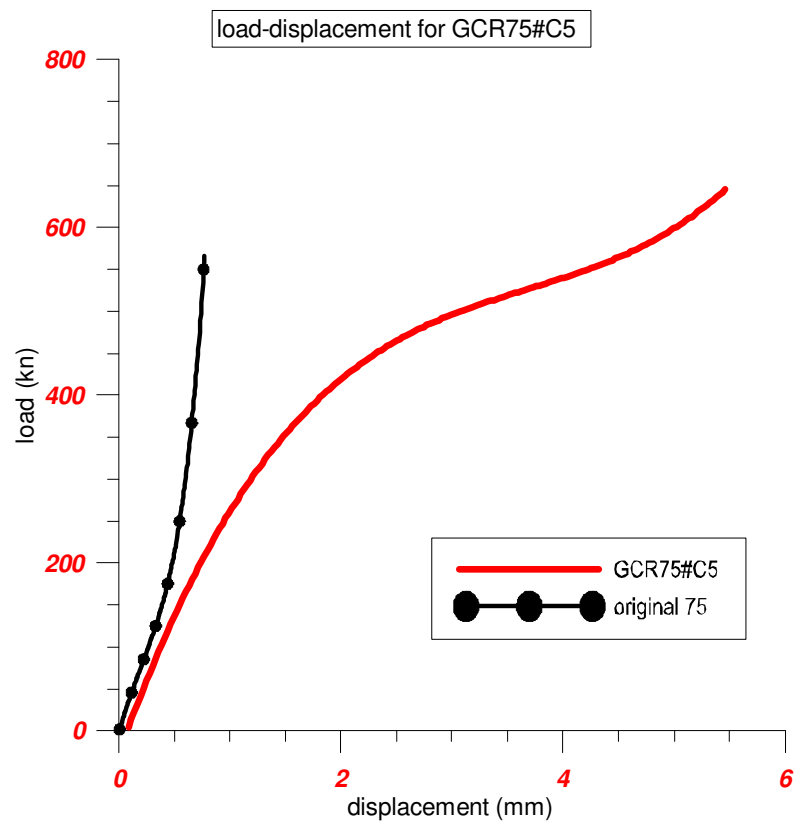

(c)Slender column $(\mathrm{kl} / \mathrm{r}=\mathbf{2 4})$

Figure 6:Load-Displacements for Each Column in Group (C) with the Original

As for group (D), it is shown clearly that, the columns performed a similar nonlinear behavior, before reaching the maximum load and it was monitored especially near failure, where concrete crushing, shearandbuckling take place.Displacements continued increasing under increasing loads until failure. In group (D) (GDR37.5, GDR50, GDR75) the maximum deflection $(8.63 \mathrm{~mm}, 7.32 \mathrm{~mm}, 5.9 \mathrm{~mm})$ respectively as in figure 7 , the differences between group (D) and control columns was $401.7 \%, 349.1 \%, 666 \%$, respectively as shown in figure 8 , a-b-c. The deflection of this group was increasedsowrapping columns with CFRP, enhanced the performance of the columns by increasing their displacement at failure and the stiffness was improved with increasing longitudinal stiffness of the FRP. The maximum load carrying of each specimen was achieving at the FRP failure point, up to the FRP was broken. 


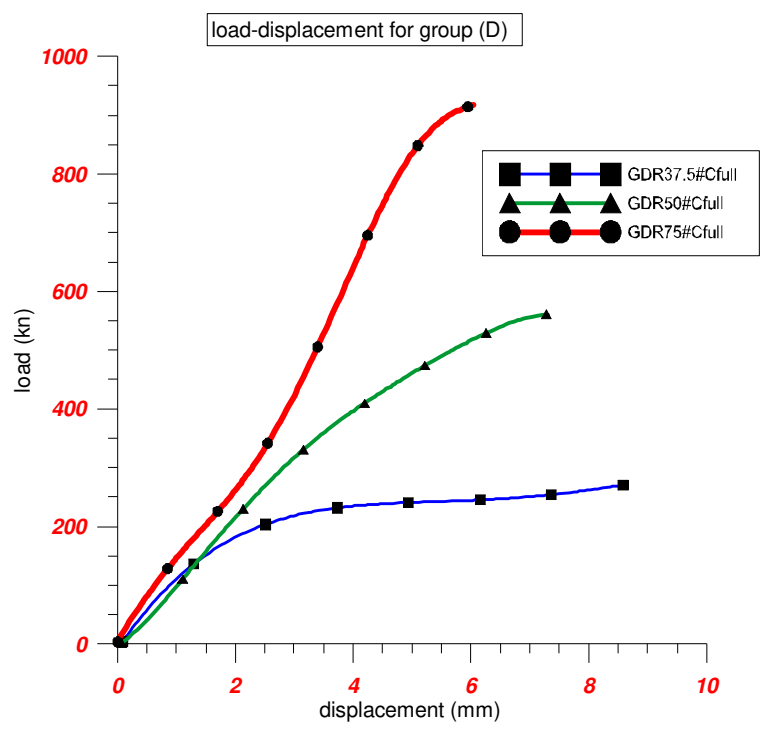

Figure 7 load-displacements for columnsin group (D)
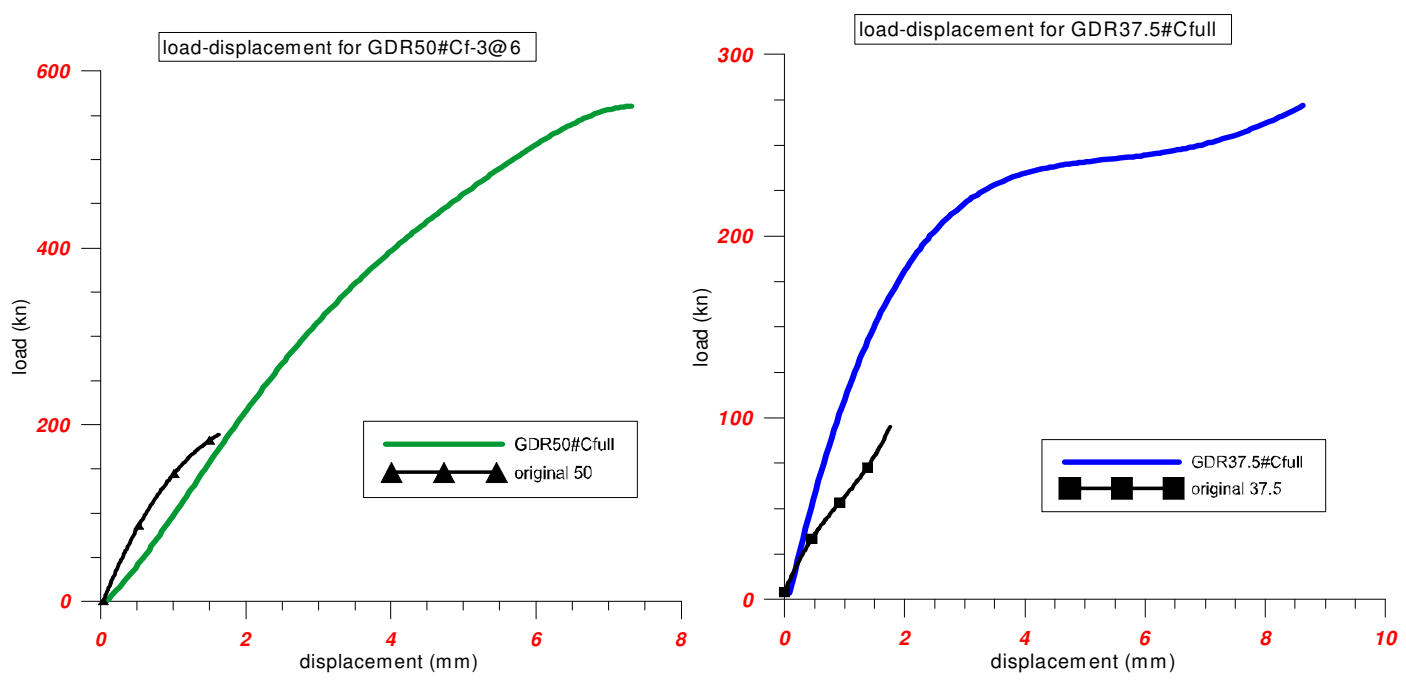

(a)Slender Column $(k \mathrm{kl} / \mathbf{r}=48)(b)$ Slender Column $(k 1 / r=36)$

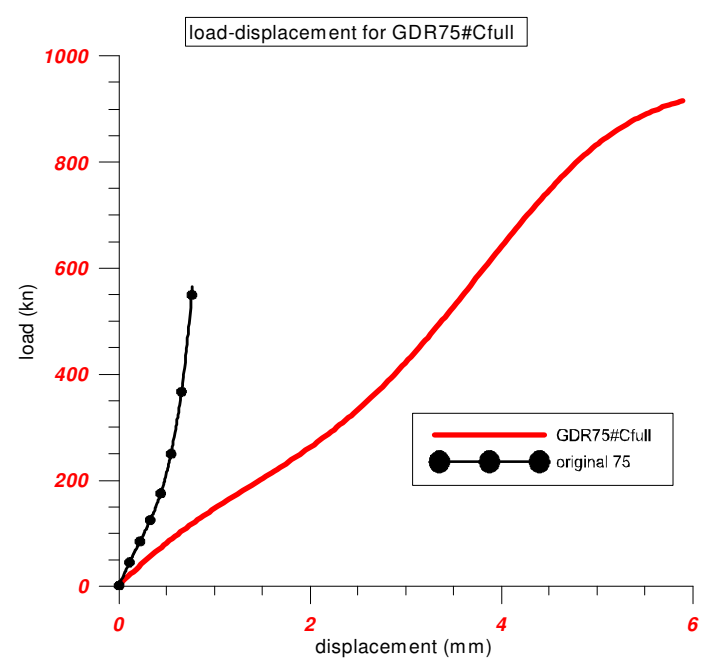

(c)Slender Column $(\mathrm{kl} / \mathrm{r}=\mathbf{2 4})$

Figure 8:Load-Displacements for Each Column in Group (D) with the Original 


\section{COLUMNS SPECIMENS' BEHAVIOR}

Figure 9 to 12, shows the effect of slenderness ratio and CFRP distribution (surface area of CFRP), on load and displacement behavior, which indicate that,the load-slenderness ratio in both crack and failure load for columns with three and five layers of CFRP (group (B) and (C)), have the same nonlinear behavior of control columns (group (A)), except columns with full CFRP (group (D)), the behavior is almost linear, this is due to the strength of CFRP, when it's fully strengthened.

While, displacement-slenderness ratio has little difference between crack and failure load, control columns have nonlinear behavior at the crack and failure load. Group (B) and (C), have a linear behavior at crack load, but at failure load group (C) change his path, due to the rupture of CFRP, and group (D) has had a nonlinearbehaviorof crack load and then became linear at failure with high displacement due to CFRP rupture also.

As for the load - surface area of CFRP, the columns with radius (37.5 and 50) mm have a similar behavior at both crack and failure load while columns with a radius $(75 \mathrm{~mm})$ have high marked deflection in its behavior at cracking load and linear behavior at failure, this indicate that the column with radius $(75 \mathrm{~mm})$ the more effective in CFRP distribution due to its geometry. Also inthe displacement - surface area the column with radius $(75 \mathrm{~mm})$ have differentbehavior from other columns due to having the large displacement in all strengthening method and due to CFRP rupture at failure.
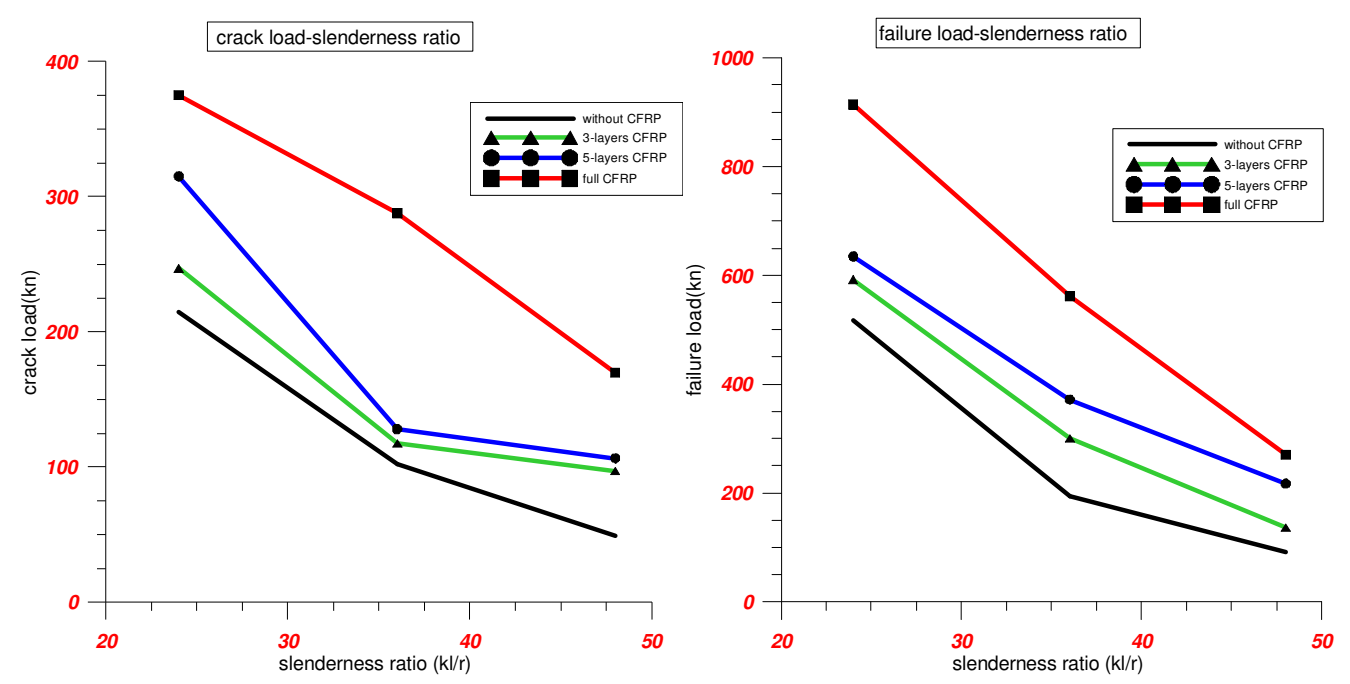

Figure9: load-slenderness ratio behaviors at crack and failure load 

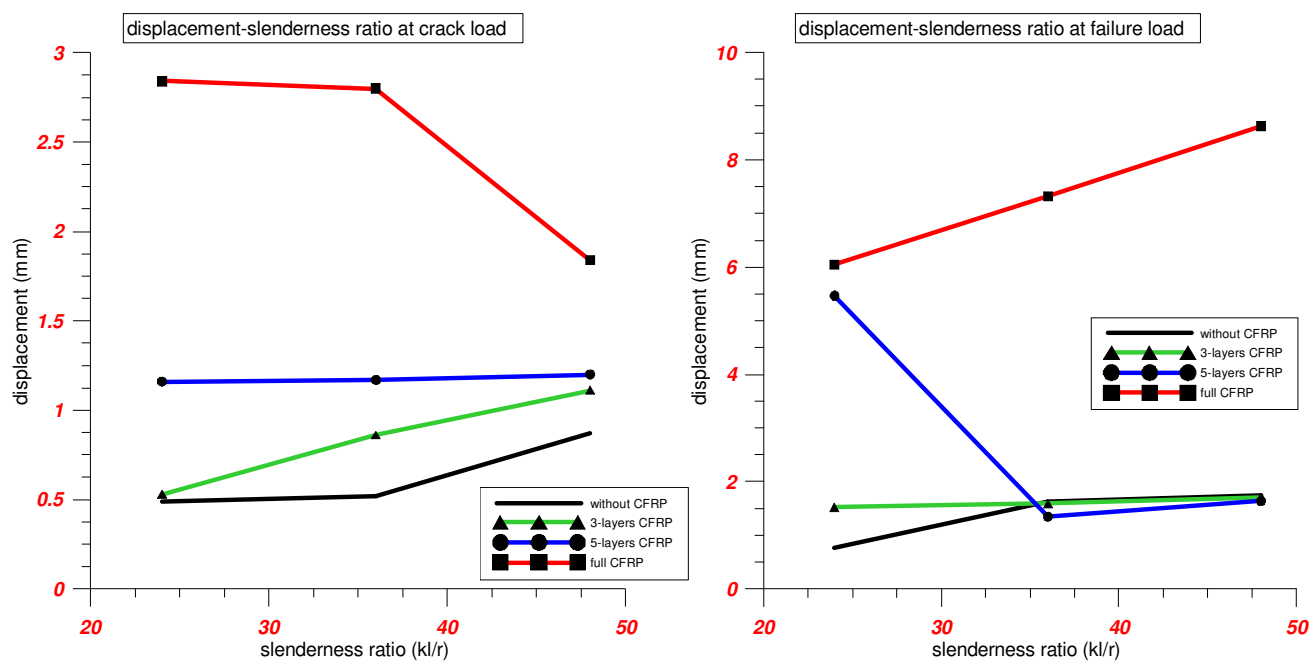

Figure 10:Displacement- Slenderness Ratio Behaviors at Crack andFailure Load
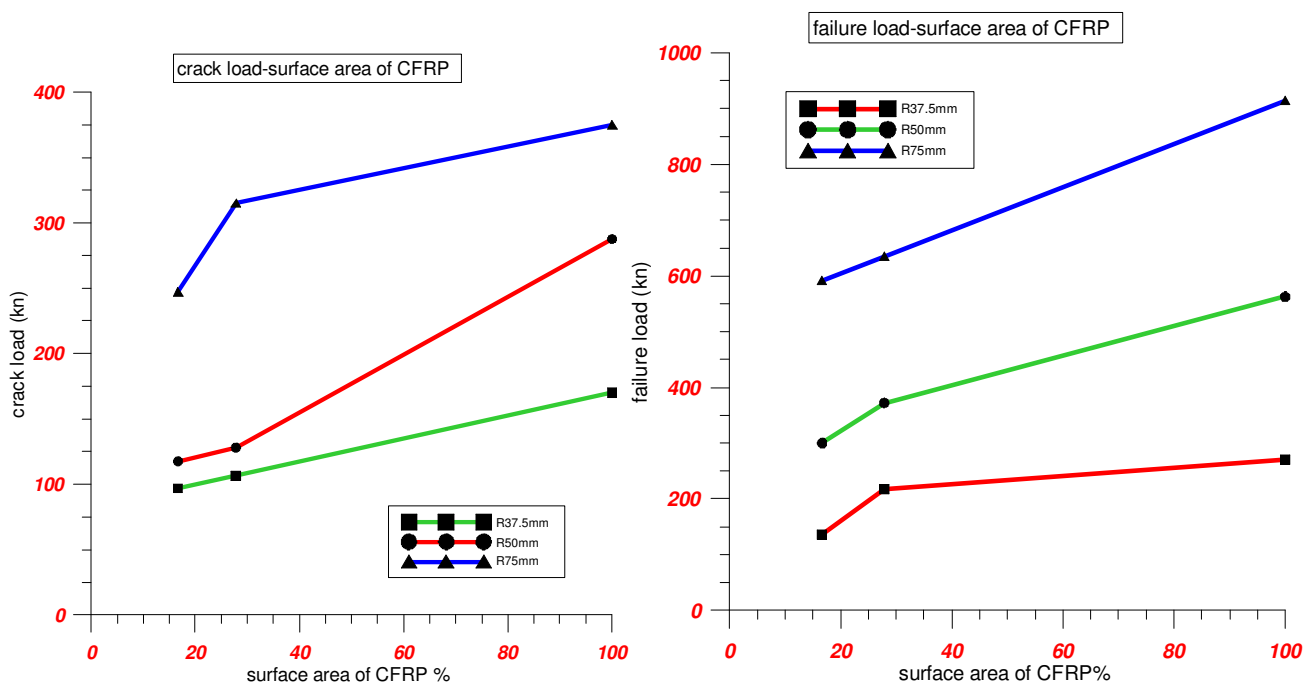

Figure 11:Load-Surface Area of CFRP Behavior at Crack and Failure Load
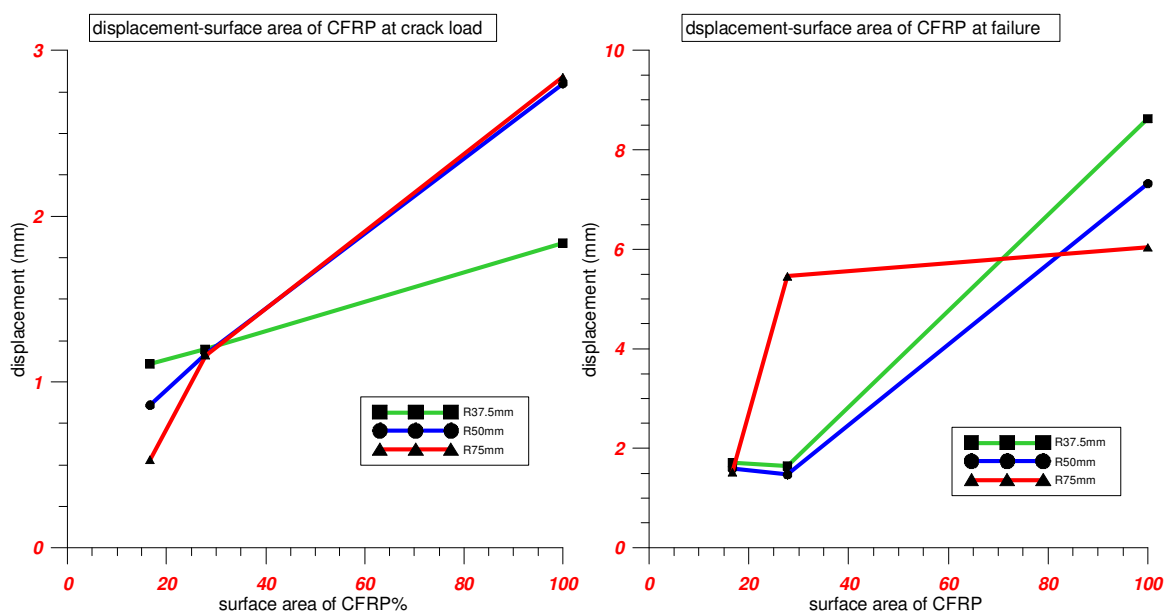

Figure 12:Displacement- Surface Area of CFRP Behavior at Crack and Failure Load 


\section{DUCTILITY OF COLUMNS}

The ductility was analyzed as well to describe the performance of the columns.Thearea under load- axial displacement curves can be an important method toexpress the ductility that obtained by using CFRP strengthening. Table 6 shows the calculated values of the columnsductility. It is clear from the table that the columns which were strengthened with CFRP performed better than control columns. The increasing in ductility is of more importance for fully strengthened columns. Also the strengthening by five layers gives more ductility than strengthening by three layers.

\section{Table 6:Area Under the Load-Axial Displacement Curves}

\begin{tabular}{|c|c|}
\hline Specimens & $\begin{array}{c}\text { Area Under the Load- } \\
\text { Displacement Curve kN } \\
\text { mm }\end{array}$ \\
\hline GAR37.5\#C0 & 90.5 \\
\hline GAR50C0 & 134.3 \\
\hline GAR75\#C0 & 150.6 \\
\hline GBR37.5\#C3 & 122.9 \\
\hline GBR50\#3 & 158 \\
\hline GBR75\#C3 & 476.2 \\
\hline GCR37.5\#C5 & 146.7 \\
\hline GCR50\#C5 & 226.2 \\
\hline GCR75\#C5 & 928.4 \\
\hline GDR37.5\#Cfull & 1782.8 \\
\hline GDR50\#Cfull & 2394 \\
\hline GDR75\#Cfull & 2737.2 \\
\hline
\end{tabular}

\section{CONCLUSIONS}

According to the analysis of the experimental results obtained in this studythatconclude Studying the effectiveness of various strengthened methods, on the varied RC column circular cross section, which has the same reinforcement details, some important findings can be drawn. The main findings of this research can be summarized as follows:

- The pure axial compressive loading test results of the circular RC columns indicate that wrapping columns with CFRP improves both the load-carrying capacity and the ductilitywithout a significant increase in a cross-section.

- A significant advantage was attained that wrapping with CFRP improved the performance of the columns by delaying the rupture of the concrete and reinforcement.

- Increasing the number of the CFRP sheets shows an increase in the compressive strength and the performance of the confined columns. It was proven that wrapping with a minimum of three-layers of CFRP sheets would be suggested to achieve important results.

- CFRP strengthened specimens shown a typical nonlinear behavior. No individual post behavior is observed as the slenderness ratio increases.

- The effect of strengthening techniques on the slenderColumns is greater than the effect on short columns. As a result of the increasingslenderness ratio of warping columns with FRP,leads on overall to decrease in the load carrying capacity and a moderate reduction in the axial deformation, which confirmsthe present experimental observations.

- The axial resistance and ductility of columns can be increased by increasing the cross sectional area. 


\section{REFERENCES}

1. A. H. K. AL-Musawi "Experimental Study of Reinforced Concrete Columns Strengthened with CFRP under Eccentric Loading

", M.Sc. Thesis, AI-Mustansiriya University, iraq, 2012.

2. X. Yang, "The engineering of construction specifications for externally bonded FRP composites". University of Missouri Rolla, 2001.

3. D. Schnerch, K. Stanford, B. Lanier, and S. Rizkalla, "Use of high modulus carbon fiber reinforced polymers (CFRP) for strengthening steel structures, " in The second international workshop on structural composites for infrastructure applications, Cairo, 2003.

4. J. Teng and L. Lam, "Compressive behavior of carbon fiber reinforced polymer-confined concrete in elliptical columns," Journal of Structural Engineering,vol. 128, pp. 1535-1543, 2002.

5. M. R. Esfahani and M. R. Kianoush, "Axial compressive strength of reinforced concrete columns wrapped with fibre reinforced polymers (FRP)," polymer (FRP), vol. 1, p. 3, 2005.

6. Y. A. Al-Salloum, "Influence of edge sharpness on the strength of square concrete columns confined with FRP composite laminates," Composites Part B: Engineering,vol. 38, pp. 640-650, 2007.

7. M. A. Silva, "Behavior of square and circular columns strengthened with aramidic or carbon fibers," Construction and Building Materials,vol. 25, pp. 3222-3228, 2011.

8. P. Taghia and S. A. Bakar, "Mechanical behaviour of confined reinforced concrete-CFRP short column-based on finite element analysis," World Applied Sciences Journal,vol. 24, pp. 960-970, 2013.

9. A. Sulaiman, H. Almansour, and H. Aoude, "MAT-722: EFFECT OF FIBER ORIENTATION ON THE BEHAVIOR OF CFRP CONFINED CONCRETE CYLINDERS," 2016.

10. J. Li and M. Hadi, "Behaviour of externally confined high-strength concrete columns under eccentric loading," Composite Structures,vol. 62, pp. 145-153, 2003.

11. M. Hadi and J. Li, "External reinforcement of high strength concrete columns," Composite Structures, vol. 65, pp. 279-287, 2004

12. M. N. Hadi, "Comparative study of eccentrically loaded FRP wrapped columns," Composite Structures, vol. 74, pp. 127-135, 2006.

13. M. N. Hadi, "The behaviour of FRP wrapped HSC columns under different eccentric loads, " Composite Structures, vol. 78, pp. 560-566, 2007.

14. P. Sadeghian, A. R. Rahai, and M. R. Ehsani, "Numerical modeling of concrete cylinders confined with CFRP composites," Journal of Reinforced Plastics and Composites,vol. 27, pp. 1309-1321, 2008.

15. A. P. D. YarubGatiaAbtan, L. D. H. F. Hassan, and L. D. H. A. Mehdi, "BEHAVIOR OF CARBON FIBER REINFORCED POLYMER STRENGTHENED REACTIVE POWDER CONCRETE COLUMNS," Journal Impact Factor,vol. 6, pp. 22-42, 2015.

16. M. Abbassi and H. Dabbagh, "Behavior of FRP-Confined Reactive Powder Concrete Columns under Eccentric Loading," Journal of Rehabilitation in Civil Engineering,vol. 2, pp. 46-64, 2014.

17. A. R. Malik and S. J. Foster, "Carbon fiber-reinforced polymer confined reactive powder concrete columns-experimental investigation," ACI Structural Journal, vol. 107, p. 263, 2010. 
18. M. El Sayed and T. El Maaddawy, "Analytical model for prediction of load capacity of RC columns confined with CFRP under uniaxial and biaxial eccentric loading," Materials and structures, vol. 44, pp. 299-311, 2011.

19. H. A. Mesbah, N.-E. Chikh, and R. Benzaid, "Performance of externally CFRP confined RC columns with changes in thickness of the wrap, slenderness of the column and shape of the section'," in Séminaire International, innovation \& valorisation en génie civil \& matériaux de construction INVACO2, 2011, pp. 1-6. 
